\title{
PREDICTION AND ANALYSIS OF POLLUTION AND CONGESTION LEVEL FOR PRESENT AND FUTURE SCENARIO ON AN URBAN ROAD NETWORK - INDIA
}

\author{
Awkash Kumar', Saloni Vijay², Rakesh Kumar³, Rashmi S Patil ${ }^{1}$, Anil Kumar Dikshit ${ }^{1}$, \\ Sunder Lal Dhingra ${ }^{4}$ \\ ${ }^{1}$ Centre for Environmental Science and Engineering, Indian institute of Technology Bombay, Mumbai- \\ 400 076, India \\ ${ }^{2}$ Department of Environmental Science and Engineering, Indian School of Mines, Dhanbad - 826004, India \\ ${ }^{3}$ National Environmental Engineering Research Institute, Council of Scientific and Industrial Research, \\ Nagpur - 440 020, India \\ ${ }^{4}$ Transportation Systems Engineering, Department of Civil Engineering, Indian institute of Technology \\ Bombay, Mumbai- 400 076, India
}

Received 5 August 2017; accepted 28 March 2018

\begin{abstract}
Due to increasing population and rising income level, most of the metropolitan cities in the world are facing problems of congestion and pollution. It is high time proper steps were taken to prevent the unbearable congestion and pollution that might occur in the near future. Before taking the mitigation measures, it is important to find out or estimate the level of congestion and pollution. Hence, the study has been conducted to assess the present and future pollution and congestion level for a highly congested Worli Road Network, Mumbai. Level of service analysis has been done for all the roads in the network to find out the congestion level. The impact of the traffic was quantified in terms of Volume/Capacity $(\mathrm{V} / \mathrm{C})$ ratio, for the coming 20 years in 10 -year intervals. The years in which any road was reaching its theoretical capacity was also identified. USEPA AERMOD has been used with proper evaluation of the model results to model the concentration of air pollutants for present and future scenario. Through the predicted results of congestion and air pollution in future, some mitigation measures are suggested.
\end{abstract}

Keywords: Pollution, Congestion, Peak Time, Long Term Impact.

\section{Introduction}

Mumbai is one of the most populated cities in India with a total population of 20.7 million and it has $4.7 \%$ population growth rate (Census, 2011). Rapidly growing urban population and economy have resulted in increasing number of vehicles in the region. This city had around two million total numbers of vehicles in the year 2012 (RTO, 2012). The increase in percentage from 1983 to 1993 (in 10 years) was 66\%, from 1993 to 2003 (in 10 years) was 50\% and from 2006 to 2012 (in 6 years) was $43 \%$ (Kumar and Joseph, 2006). Traffic congestion has been one of major issues that are being faced by most metropolitan cities in India. The rapid growth of traffic is overwhelming to carrying

${ }^{1}$ Corresponding author: awkash@iitb.ac.in 
capacity of the city and causing more risk for health and safety of society (Pawar and Patil, 2015). Comprehensive Transportation Study was carried out to improve the traffic and transportation facilities in Mumbai Metropolitan Region for a total period of 20 years (CTS, 2008). CTS reported various traffic surveys to collect data regarding traffic and travel characteristics of the region. It helped to identify and quantify the environmental, social, economic and financial perspective for traffic management. Traffic congestion wastes time, idling of engine occurs more energy consumption and causes pollution (Mohan Rao and Ramachandra Rao, 2012). With the growing pollution and population, local authorities have forced to move industries at the outskirts of the city. So, traffic emissions are now the major constituent of local air pollution as compared to the previous scenario (two decades ago) when industrial emissions were dominating. Due to high density of vehicles of various types at traffic junctions, vehicular pollution is a prominent problem in the terms of health caused by air pollution (Patankar and Trivedi, 2011; Kumar et al., 2016). The emitted pollutions in atmosphere due to traffic, affect the air quality adversely. The pollution level is high because of maximum emission during the peak time (Gokhale, 2011; 2012; Choudhary and Gokhale, 2016). Roads loaded with traffic have high air pollution exposure to public (Brigs et al., 2000).

At present time, air quality status needs to be known in order to make policies regarding reducing air pollution. However, in developing countries like India, air monitoring stations are very few. Air quality models are tools to predict concentration of air pollutants with the help of mathematical formulation. It can help to analyse the impact of concentration of air pollutant for future impact and control scenarios (Abdul-Wahab et al., 2011). These provide spatial and temporal variations of concentrations of air pollutant using the emission, meteorological and topographical parameters (Gulia et al., 2015). Therefore, air quality models can be used to predict concentration for long term impact scenario. The classification of air dispersion models is done as point, area or line source models according to the pollutions sources to be modelled. Line source models are used to predict the dispersion of pollutants due to vehicles on highways or roads where pollutants are emitted continuously by vehicles (Sharma et al., 2004). Many research institutes have developed a number of line source models for predicting the pollutants concentration due to vehicles (Nagendra and Khare, 2002). Most widely used line source models are Gaussian based (Sivacoumar and Thanasekaran, 1999). However, USEPA has developed Industrial Source Complex model for considering all sources together to predict concentration of air pollutants (EPA, 2003a).

In present investigation, long term traffic impact assessment has been carried out for highly congested road network in Worli, Mumbai and its near-by area. Vehicles are the only major source of air pollution as no major industry is situated in this area. The road network around Worli was analysed to determine its performance in observed traffic of the year 2015 and the projected traffic of the coming 20 years. Volume by capacity ratio and Level of service (LoS) was calculated, as per Indian Road Congress (IRC: 106-1990) recommendations, and selected as a measure of the network performance. To predict vehicular pollution in this area, AERMOD dispersion model has been used. It is a plume model for steady state which considers Gaussian dispersion in horizontal distribution and bi-Gaussian 
probability density function in vertical. Modelling is done for three major pollutants namely $\mathrm{NO}_{\mathrm{X}}, \mathrm{CO}$ and $\mathrm{PM}$.

\subsection{AERMOD}

The American Meteorology SocietyEnvironmental Protection Agency Regulatory Model (AERMOD) is a software package based on Gaussian plume equation used for air quality analysis. It is developed by the USEPA (Cimorelli et al., 2004). AERMOD has been used for environmental impact assessment in many countries (Seangkiatiyuth et al., 2011; CPCB, 2008; Kumar et al., 2015; 2016; Mohan et al., 2011)). In India, ISCST3 is regulatory model but results of AERMOD are accepted because it has been upgraded with many algorithms for getting more accurate results. AERMOD has recently been added to the list of recommended models for regulatory applications. In AERMOD modelling processes, meteorological observation data of surface and upper air are required ( $\mathrm{Ma}$ et al., 2013). It is a refined dispersion model for simple and complex terrain for receptors within $50 \mathrm{~km}$ of a modelled source (Mokhtar et al., 2014). In this study, vehicular emissions are modelled using AERMOD. All the roads in the study network are considered as linevolume sources. Background concentration is not taken into account.

\subsection{Scope of the Study}

The entire study can broadly be broken down into the following tasks:
- Visit the site and understand the existing traffic pattern;

- Collect relevant data through primary and secondary surveys for model development and analysis. This includes the number of vehicles in category wise for entire road network and meteorological data for air quality modelling;

- Study the long term traffic impact on the road network in the terms of level of service based on future changes in the traffic;

- Preparation of emission inventory for vehicular sources for entire road network;

- Assess long term air quality level using air quality model due to the traffic load;

- Comparing the same with permissible limits and suggestions for improvement.

\section{Study Area}

Mumbai is located on India's west coast on a peninsula originally composed of seven islets (Joseph et al., 2003). The Latitude and Longitude of the study area is $\mathbf{1 8 . 9 8}$ and 72.81 respectively. The study area is around 2 kilometres from east-to-west and 3 kilometres from north-to-south as shown in Figure 1. The roads in the study network are highly congested. Study area comprises of twelve roads running nearby "Worli Region". The roads and their representation are given in Table 1 . High number of vehicles passes daily through Tardeo road and Pedar road in order to go to Marine Drive Chowpatty. 


\section{Table 1}

Road Network of Study Region and Their Representation

\begin{tabular}{|c|c|c|c|}
\hline Roads & Representation & Roads & Representation \\
\hline Haji Ali to Tardeo Road & $\mathrm{AB}$ & August Kranti to Mahalaxmi & JE \\
\hline Haji Ali to Pedar Road & $\mathrm{AC}$ & Pedar Road to Babulnath Temple & FG \\
\hline Haji Ali to Keshavrao Khade & $\mathrm{AD}$ & Pedar Road & $\mathrm{CF}$ \\
\hline August Kranti to Grant Road & $\mathrm{JK}$ & Charni Road to Marine Drive & GI \\
\hline $\begin{array}{c}\text { One way Dahnukar Marg, } \\
\text { Jaslok Hospital } \\
\end{array}$ & LM & $\begin{array}{c}\text { One way Dahnukar Marg, In front of } \\
\text { Navjot Gamadia Marg }\end{array}$ & NO \\
\hline $\begin{array}{l}\text { Hughes Road (Opera House } \\
\text { to Pedar Road) }\end{array}$ & $\mathrm{FH}$ & $\begin{array}{l}\text { Warden Road (Mahalaxmi Temple to } \\
\text { Brach Candy) }\end{array}$ & $\mathrm{CE}$ \\
\hline
\end{tabular}

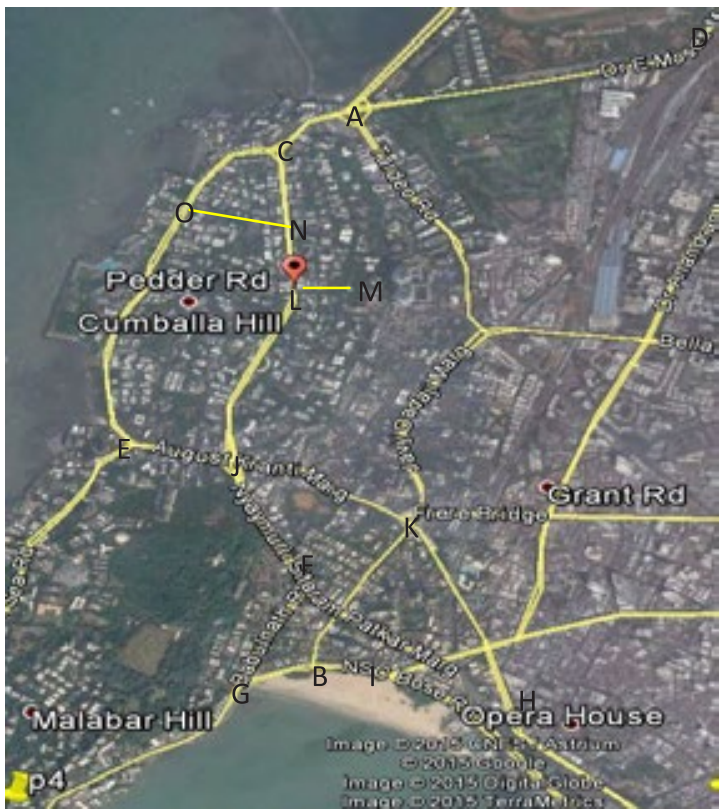

Fig. 1.

Study Area "Pedar Road Network"

Note: Legend $A$ to $O$ are given in Table 1.

\section{Methodology}

Methodology adopted for the traffic analysis:

1. The first step was to calculate the traffic volume of the road network for coming twenty years $(2015,2025$, and 2035) with the growth rate of $5 \%$ per year. This was taken from the Western Freeway
Sea Link, Maharashtra State Road Development Corporation Limited (MSRDC) where rapid environmental impact assessment was carried out for Pedar Road viaduct (MSRDC, 2006);

2. Volume of the traffic is converted to PCU (passenger car unit) from the number of vehicles by using appropriate conversion factor for each type of vehicle; 
3. The relevant Design Service Volume (DSV) of each road is taken as the capacity, as per IRC 106-1990;

4. Level of Service (LoS) is identified for each road for each respective year on the basis of Volume by Capacity ratio for the road.

\subsection{Methodology Adopted for the Level of Air Pollution analysis}

The schematic methodology for predicting air pollution level has been presented in Figure 2 and steps are given point wise below:

1. First step was to prepare emission inventory using details of field traffic data and their respective emission factors. Number of vehicles were counted and then multiplied with suitable emission factor taken from the draft report on "Emission Factor Development for Indian Vehicles” by the Automotive Research Association of India (ARAI), Pune to calculate the concentration of different air pollutants including $\mathrm{NO}_{x}, \mathrm{CO}$ and PM (ARAI, 2007). The vehicle emission factors for Indian cities have been developed by ARAI for PM, not specifically for $\mathrm{PM}_{10}$ or $\mathrm{PM}_{2.5}$;

2. Meteorological data i.e. hourly wind speed, wind direction and temperature is processed using AERMET (AERMOD meteorological pre-processor);

3. Terrain data is processed using AERMAP (AERMOD terrain preprocessor);

4. Modelling is done through AERMOD for determining present air quality. The output of AERMET and AERMAP served as an input to AERMOD. It gave the 24-hourly maximum concentration of the period and 1-hourly average concentration of period for pollutants over the region;

5. Concentration is predicted for coming 20 years (2025 and 2035) by following the same methodology as for 2015 .

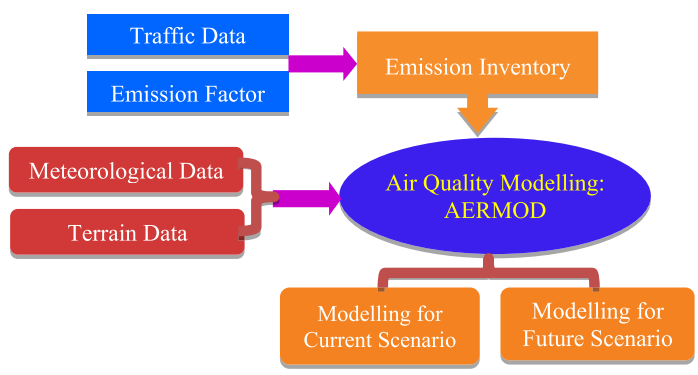

Fig. 2.

Schematic Work Methodology for Air Quality Modelling

\section{Results and Discussion}

The results of traffic impact analysis and air quality modelling have been carried out and discussed into next sections.

\subsection{Results of Traffic Congestion Analysis}

Traffic analysis has been done for all the roads in the network. Morning time and 
evening time when maximum number of vehicles are present is given in Table 2. Correspondingly, level of service and congestion is also shown in Figure 3-5 for present scenario (2015) and future scenario (2025 and 2035) respectively.

Table 2

Selected Morning Peak Time and Evening Peak Time for the Period

\begin{tabular}{|c|c|c|}
\hline Roads & Morning Peak Time & Evening Peak Time \\
\hline AB & $10.00-11.00$ & $18.00-19.00$ \\
\hline AC & $10.00-11.00$ & $19.00-20.00$ \\
\hline AD & $11.00-12.00$ & $19.00-20.00$ \\
\hline CE & $11.00-12.00$ & $19.00-20.00$ \\
\hline CF & $10.00-11.00$ & $19.00-20.00$ \\
\hline FG & $11.00-12.00$ & $19.00-20.00$ \\
\hline FH & $11.00-12.00$ & $19.00-20.00$ \\
\hline GI & $10.00-11.00$ & $19.00-20.00$ \\
\hline JK & $11.00-12.00$ & $20.00-21.00$ \\
\hline JE & $11.00-12.00$ & $20.00-21.00$ \\
\hline LM & $11.00-12.00$ & $20.00-21.00$ \\
\hline NO & $10.00-11.00$ & $20.00-21.00$ \\
\hline
\end{tabular}

Table 3

V/C Ratio for Roads of Network

\begin{tabular}{|c|c|c|}
\hline S.No. & Roads & V/C \\
\hline 1 & $\mathrm{AB}$ & $>1$ \\
\hline 2 & $\mathrm{AC}$ & $>1$ \\
\hline 3 & $\mathrm{AD}$ & $>1$ \\
\hline 4 & $\mathrm{CF}$ & $>1$ \\
\hline 5 & $\mathrm{FG}$ & $>1$ \\
\hline 6 & $\mathrm{LM}$ & $>1$ \\
\hline 7 & $\mathrm{NO}$ & $>1$ \\
\hline
\end{tabular}

Maximum numbers of vehicles on most of the roads in the network are present between 10:00 A.M. and 12:00 P.M. in morning and between 19:00 P.M. and 21:00 P.M. in the evening. But at Tardeo Road, maximum numbers of vehicles are present between 18:00 P.M. and 19:00 P.M. in the evening. The roads which are reaching their theoretical capacity in 2015, based on IRC recommendations, assuming the $5 \%$ growth rate, are shown in the Table 3. Morning peak congestion is significantly lesser than the evening peak congestion. Haji Ali to Pedar road has maximum congestion. According to this study, total seven roads in the network are highly congested especially during evening peak time. It has been observed that all the roads in the network are reaching their theoretical capacity in future (2025) especially in evening peak time. Hence, proper steps must be taken in order to avoid such situation.

\subsection{Results of Air Quality Modelling}

Air quality modelling was carried out to make concentration plot for air pollutants spatially over the region. In this study, the modelling was carried out using AERMOD for $\mathrm{CO}, \mathrm{NO}_{\mathrm{x}}$ and $\mathrm{PM}$ with the help of 
respective emission inventory of all vehicles and meteorological data. This has been done for the month of March, 2015 to find out their concentration levels in the study domain. March month falls in the pre-monsoon season and it is neither critical like December nor favourable like July in dispersion and wash out point of view. Wind rose diagram for the month of March has been shown in

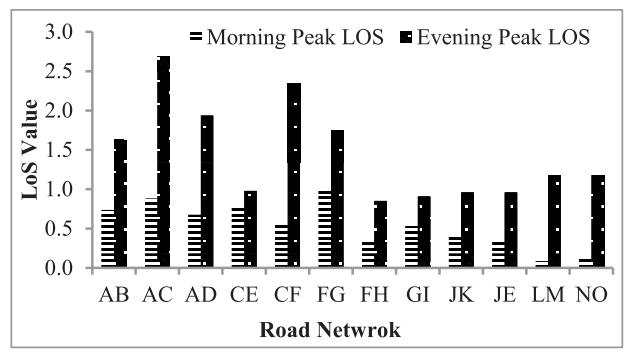

Fig. 3.

Level of Traffic Congestion in 2015

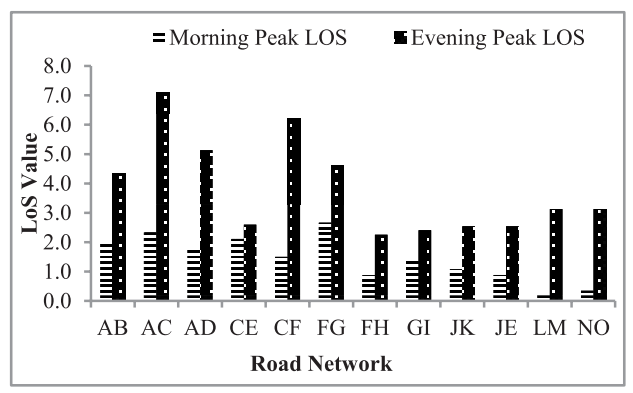

Fig. 5.

Level of Traffic Congestion in 2035

\subsection{Comparison of AERMOD Results with Monitored Data}

AERMOD output has been compared with the monitored data in Table 4. Here ambient air quality is being monitored at two locations. Model concentration is lower than observed concentration because meteorological data used in the model is from a monitoring station $2 \mathrm{~km}$ away
Figure 6. The model results were compared with observed values of concentration for the respective air pollutants. 24-hourly maximum concentration and hourly average concentrations of period have been plotted for all three pollutants for the year 2015 and then this concentration has been compared with the observed concentration of future scenario year 2025 and 2035.

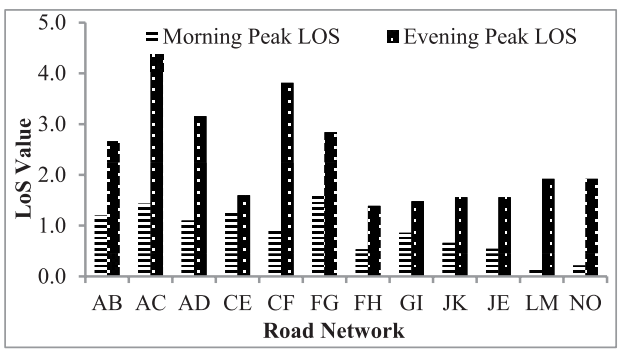

Fig. 4.

Level of Traffic Congestion in 2025

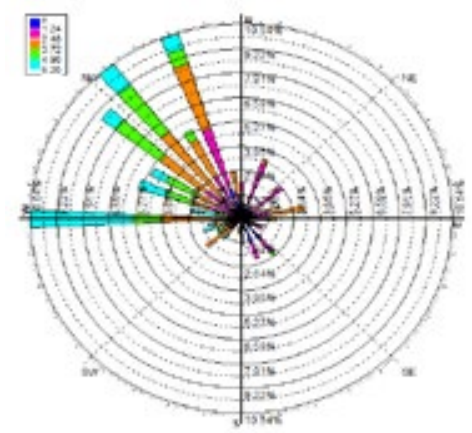

Fig 6.

Wind Rose for the Period

at Worli Sea Face where wind speed was higher than these roads. In the case of PM, model concentration was significantly lower compared to observed concentration. PM emission from tail pipe of vehicles is very low and observed concentration includes re-suspension effect of vehicle movement. $100 \mu \mathrm{g} / \mathrm{m}^{3}$ was estimated from re-suspension of the vehicles in a recent study of BandraWorli Sea Link study (NGT, 2015). 
Table 4

Comparison of Simulated Concentration $\left(\mu \mathrm{g} / \mathrm{m}^{3}\right)$ with Ambient Observed Concentration $\left(\mu \mathrm{g} / \mathrm{m}^{3}\right)$

\begin{tabular}{|c|c|c|c|c|}
\hline Pollutant & Location & Simulated Conc. & Observed Conc. & \% Error \\
\hline CO & Point N & 221 & 801 & -0.72 \\
\hline & Point J & 195 & 900 & -0.78 \\
\hline NO $_{\mathbf{x}}$ & Point N & 28 & 36 & -0.22 \\
\hline & Point J & 36 & 43 & -0.16 \\
\hline PM & Point N & 1 & 98 & -0.99 \\
\hline & Point J & 2 & 105 & -0.98 \\
\hline
\end{tabular}

\subsection{CO Hourly Average Concentration of Period for the Year 2015}

Hourly average concentration plot of period for $\mathrm{CO}$, emitted by vehicles in the study area, is shown in Figure 7(a). Average concentration of $\mathrm{CO}$ in the road network is less than the 24-hour maximum concentration. Maximum concentration

of $\mathrm{CO}$ is $167 \mu \mathrm{g} / \mathrm{m}^{3}$ at Haji Ali Junction. Warden Road has lowest concentration of $60 \mu \mathrm{g} / \mathrm{m}^{3}$. Average concentration of $\mathrm{CO}$ is also projected for future. Comparison of average concentration plot for the years 2015, 2025 and 2035 at the Haji Ali Junction has been presented in the Figure 7(b). This concentration is predicted to reach $444 \mu \mathrm{g}$ / $\mathrm{m}^{3}$ in the year 2035 .

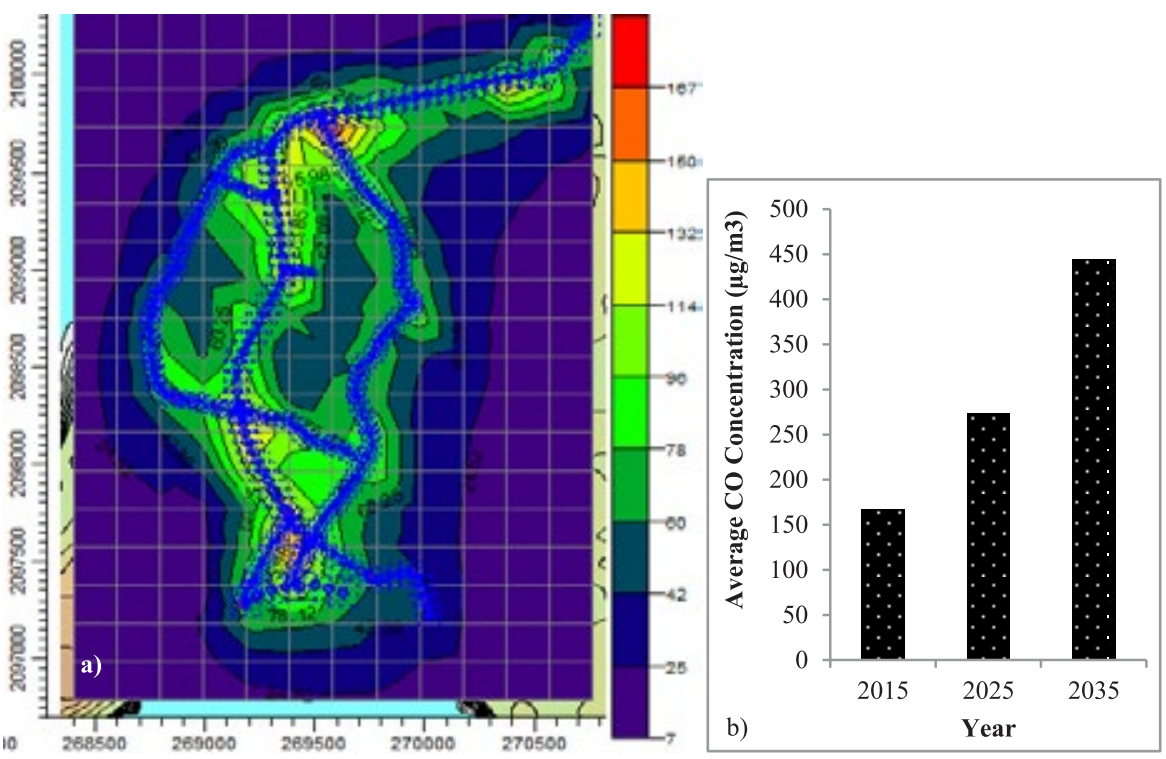

Fig. 7.

(a) Hourly Average Concentration Plot of Period for the Year 2015 and (b) Maximum Concentration Over the Region for CO for the Year 2015, 2025 and 2035 

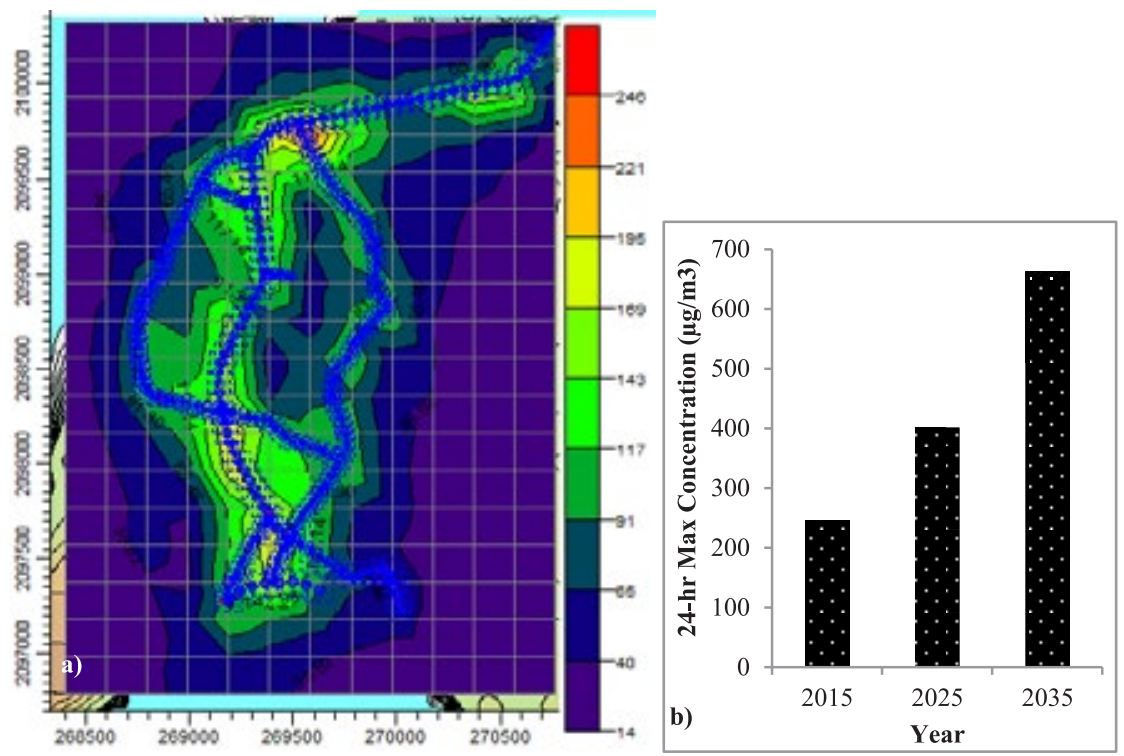

Fig. 8.

(a) 24-Hour Maximum Concentration Plot for the Year 2015 and (b) Maximum Concentration over the Region for CO for the Year 2015, 2025 and 2035

\subsection{CO 24-Hour Maximum Concentration for the Year 2015}

CO 24-hour maximum concentration plot, emitted by vehicles in the study area, is shown in Figure 8(a). Maximum 24-hour concentration of CO $\left(246 \mu \mathrm{g} / \mathrm{m}^{3}\right)$ is found at Haji Ali Junction as it has maximum density of vehicles. $221 \mu \mathrm{g} / \mathrm{m}^{3} \mathrm{CO}$ concentrations are near Babulnath Temple. Warden road has lowest concentration of $91 \mu \mathrm{g} / \mathrm{m}^{3}$. In March, 2015, wind blows from north-west corner for maximum period of time. Using the same meteorology data in this region for coming 25 years, $\mathrm{CO}$ concentration is predicted for future scenario. Comparison of maximum 24-hour average concentration plot for the years 2015, 2025 and 2035 at the Haji Ali Junction has been presented in the Figure $8(\mathrm{~b})$. This concentration will reach $663 \mu \mathrm{g} /$ $\mathrm{m}^{3}$ in the year 2035 according to present investigation.

\subsection{NO Hourly Average Concentration of Period for the Year 2015}

$\mathrm{NO}_{\mathrm{x}}$ average concentration plot of period, emitted by vehicles in the study area, is shown in Figure 9 (a). Average concentration of $\mathrm{NO}_{x}$ in the road network is less than the 24hour and annual maximum concentration. Average concentration of $\mathrm{NO}_{x}$ is $50 \mu \mathrm{g} / \mathrm{m}^{3}$ at Haji Ali Junction. Warden Road has lowest concentration of $18 \mu \mathrm{g} / \mathrm{m}^{3}$. Comparison of 
average concentration plot of $\mathrm{NO}_{\mathrm{x}}$ for the years 2015, 2025 and 2035 at the Haji Ali Junction has been presented in the Figure 9 (b). This concentration is predicted to reach $82 \mu \mathrm{g} / \mathrm{m}^{3}$ in 2025 and $133 \mu \mathrm{g} / \mathrm{m}^{3}$ in the year 2035 .

\subsection{NO 24 -Hour Maximum Concentration for the Year 2015}

$\mathrm{NO}_{x}$ maximum 24-hour maximum concentration plot, emitted by vehicles in the study area, is shown in Figure 10 (a).

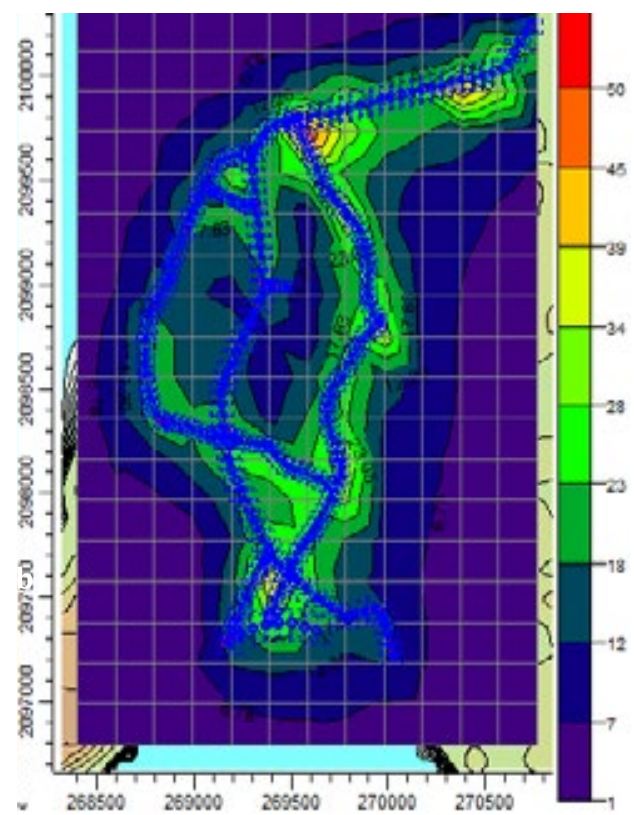

Maximum concentration of $\mathrm{NO}_{\mathrm{x}}$ is $75 \mu \mathrm{g} /$ $\mathrm{m}^{3}$. It is also found at Haji Ali Junction. $67 \mu \mathrm{g} / \mathrm{m}^{3} \mathrm{NO}_{x}$ concentrations are near Babulnath Temple. Warden Road has lowest concentration of $28 \mu \mathrm{g} / \mathrm{m}^{3}$. Using the same methodology as that for CO, 24-hour Maximum concentration of $\mathrm{NO}_{x}$ is predicted for future scenario. Comparison of maximum 24-hour average concentration plot for the years 2015, 2025 and 2035 at the Haji Ali Junction has been presented in the Figure 10 (b). This concentration will reach $201 \mu \mathrm{g} / \mathrm{m}^{3}$ in 2035 according to present investigation.

Fig. 9.

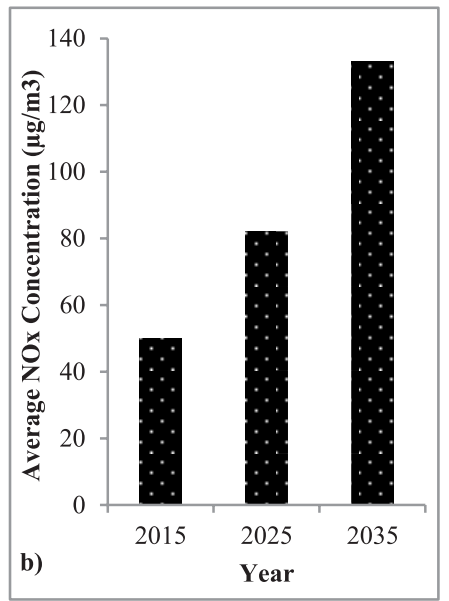

(a) Hourly Average Concentration Plot of Period for the Year 2015 and (b) Maximum Concentration Over the Region for $\mathrm{NO}_{x}$ for the Year 2015, 2025 and 2035 


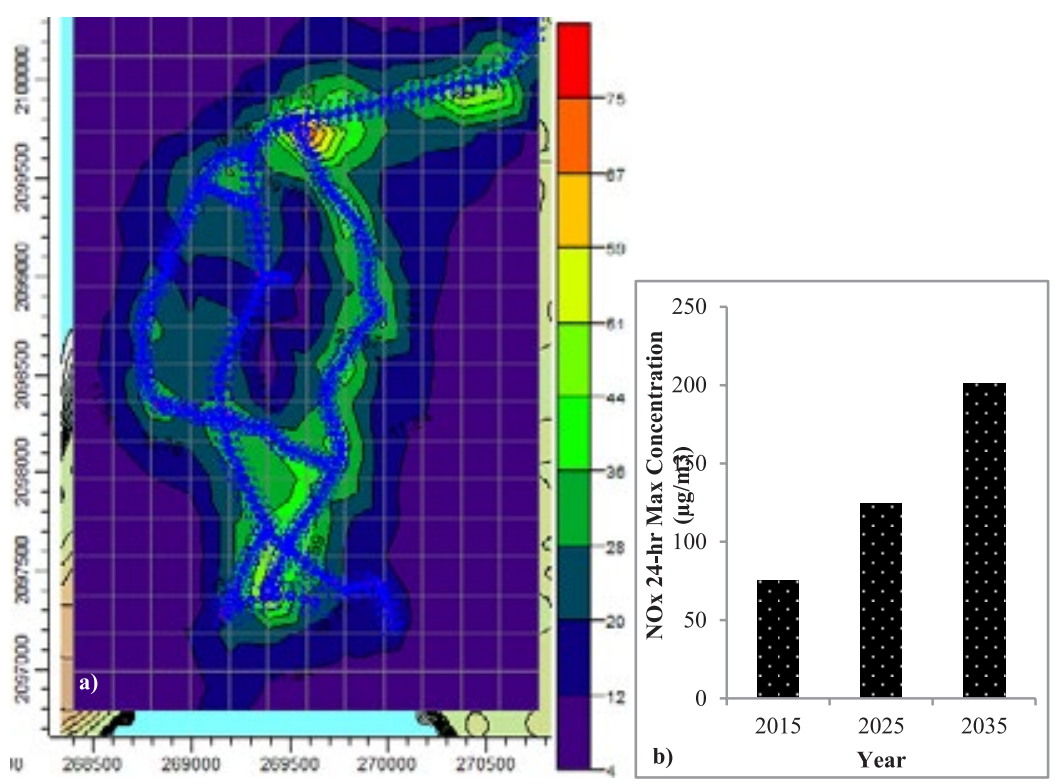

Fig. 10.

(a) 24-Hour Maximum Concentration Plot for the Year 2015 and (b) Maximum Concentration over the Region for $\mathrm{NO}_{x}$ for the Year 2015, 2025 and 2035

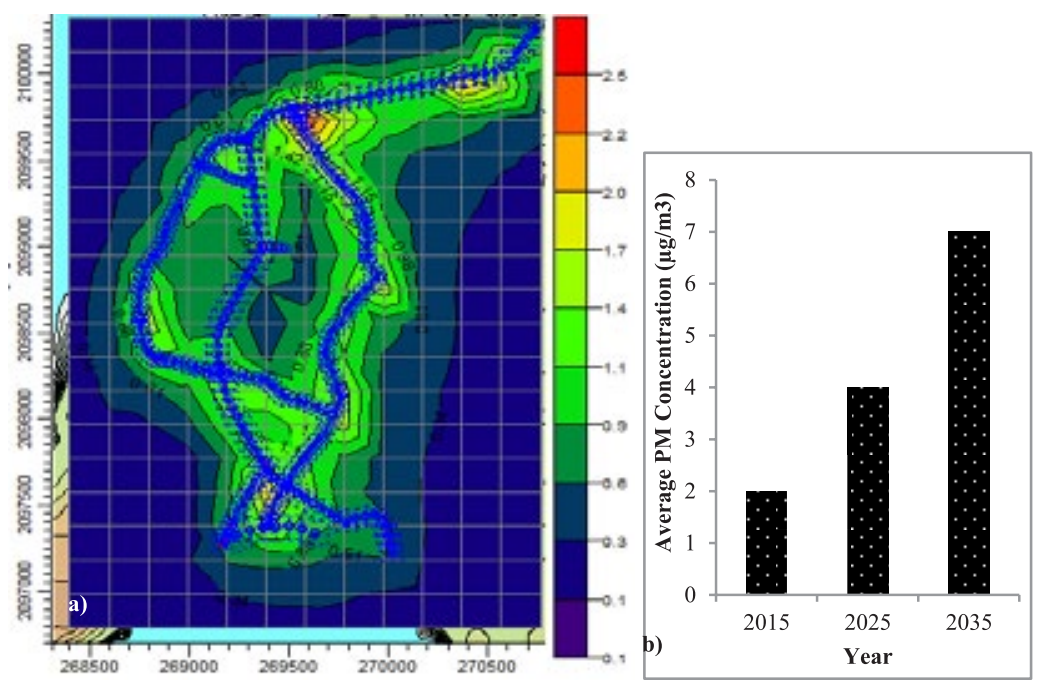

Fig. 11.

(a) Hourly Average Concentration Plot of Period for the Year 2015 and (b) Maximum Concentration Over the Region for PM for the Year 2015, 2025 and 2035 


\subsection{PM Hourly Average Concentration of Period for the Year 2015}

PM average concentration plot of period emitted by vehicles in the study area is shown in Figure 11 (a). Average concentration of PM in the road network is less than the 24-hour maximum concentration. Average concentration of PM is $2.5 \mu \mathrm{g} / \mathrm{m}^{3}$ at Haji Ali Junction. Warden Road has lowest concentration of $1.1 \mu \mathrm{g} / \mathrm{m}^{3}$. Comparison of average concentration of PM for the years 2015, 2025 and 2035 at the Haji Ali Junction has been presented in the Figure $11(\mathrm{~b})$. This concentration is predicted to reach $4 \mu \mathrm{g} /$ $\mathrm{m}^{3}$ in the year 2025 and $7 \mu \mathrm{g} / \mathrm{m}^{3}$ in the year 2035.
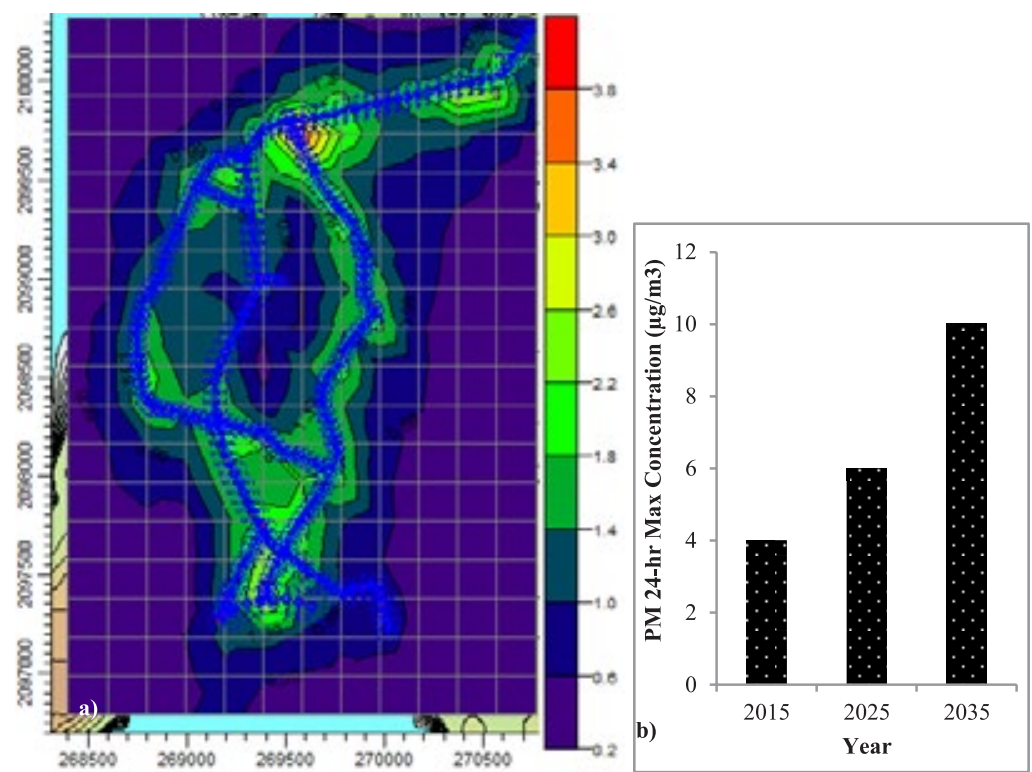

Fig. 12.

(a) 24-Hour Maximum Concentration Plot for the Year 2015 and (b) Maximum Concentration Over the Region for PM for the Year 2015, 2025 and 2035

\subsection{PM Hourly Average Concentration of Period for the Year 2015}

PM average concentration plot of period emitted by vehicles in the study area is shown in Figure 11 (a). Average concentration of PM in the road network is less than the 24-hour maximum concentration. Average concentration of PM is $2.5 \mu \mathrm{g} / \mathrm{m}^{3}$ at Haji Ali Junction. Warden Road has lowest concentration of $1.1 \mu \mathrm{g} / \mathrm{m}^{3}$. Comparison of average concentration of PM for the years 2015, 2025 and 2035 at the Haji Ali Junction has been presented in the Figure 11 (b). This concentration is predicted to reach $4 \mu \mathrm{g} /$ $\mathrm{m}^{3}$ in the year 2025 and $7 \mu \mathrm{g} / \mathrm{m}^{3}$ in the year 2035 . 


\section{Table 5}

Comparison of Maximum Concentration for Pollutants for Current and Future Scenarios

\begin{tabular}{|l|l|l|l|l|l|l|l|}
\hline Scenarios & \multicolumn{2}{|l|}{ Year 2015 } & \multicolumn{2}{l|}{ Year 2025 } & \multicolumn{2}{l|}{ Year 2035 } & $\begin{array}{l}\text { Permissible } \\
\text { Limit }\left(\mu \mathrm{g} / \mathrm{m}^{3}\right)\end{array}$ \\
\hline Pollutants & Conc. $\left(\mu \mathrm{g} / \mathrm{m}^{3}\right)$ & Ratio & Conc. $\left(\mu \mathrm{g} / \mathrm{m}^{3}\right)$ & Ratio & Conc. $\left(\mu \mathrm{g} / \mathrm{m}^{3}\right)$ & Ratio & ( \\
\hline $\mathrm{NO}_{\mathrm{x}}$ & 246 & 1 & 401 & 1.63 & 653 & 2.655 & $2000(8 \mathrm{hours})$ \\
\hline $\mathrm{PM}$ & 75 & 1 & 124 & 1.653 & 201 & 2.68 & 40 \\
\hline
\end{tabular}

Note: Permissible Limit by (CPCB, 2009)

Traffic congestion will reach at an alarming level in the near future before the year 2025. Increase in number of vehicles will also affect the ambient air quality as shown in Table 5. It is high time proper steps were taken. Some plans have been proposed to mitigate the issues of air pollution and congestion. Concentrations of all three pollutants predicted for future scenario (2025 and 2035) were compared to that of year 2015. It was observed that the concentration ratio for all the pollutants in the year 2025 and 2035 increased by the factor of around 1.6 and 2.6 respectively.

\subsection{Mitigation Measures}

Some traffic and emission mitigations can be:

- Use of secondary control systems such as selective catalytic systems or oxidizing agent at emission source;

- Less time delay at Haji Ali traffic junction;

- Traffic management for fast movement of vehicles with ideal speed;

- Construction of flyover at Haji Ali traffic junction;

Passive control potential of trees and on-street parked cars in reduction of air pollution exposure (Abhijith and Gokhale, 2015).

\section{Conclusion}

Traffic congestion and air quality status is predicted in Worli Region, Mumbai. This region is highly congested and polluted due to large number of vehicles present on the road network. It has been found that all the roads in the network will reach their theoretical capacity in the future (2025). Since most of the vehicles on Pedar Road and Tardeo Road go directly to Chowpatty, mitigation measures, such as construction of a highway from Haji Ali junction to Marine Drive Chowpatty, should be undertaken. Due to a large number of vehicles, traffic emission is also high. To reduce air pollution due to traffic, secondary control systems, such as selective catalytic systems or oxidizing agent, should be used at the emission source.

\section{References}

Abdul-Wahab, S.; Sappurd, A.; Al-Damkhi, A. 2011. Application of California Puff (CALPUFF) model: a case study for Oman, Clean Technologies and Environmental Policy 13(1): 177-189.

Abhijith, K.V.; Gokhale, S. 2015. Passive control potentials of trees and on-street parked cars in reduction of air pollution exposure in urban street canyons, Environmental Pollution 204: 99-108. 
ARAI. 2007. Emission Factor development for Indian Vehicles, Air quality monitoring project-Indian Clean Air Programme (ICAP), ARAI, Pune, India. 89 p.

Briggs, D.J.; de Hoogh, C.; Gulliver, J.; Wills, J.; Elliott, P.; Kingham, S.; Smallbone, K. 2000. A regression based method for mapping traffic related air pollution: application and testing in four contrasting urban environments, Science of the Total Environment 253(1-3): 151-167.

Census data. 2011. Census of India Organisation, Ministry of Home Affairs, Government of India. Available from internet: <http://www.censusindia. gov.in/2011-Common/CensusData2011.html>.

Cimorelli, A. J.; Perry, S. G.; Venkatra, A.; Weil, J. C.; Paine, R. J.; Wilson Robert B., Lee R. F., Peters W. D., Brode R. W., Paumie J. O. 2004. AERMOD: Description of Model Formulation EPA-454/R-03-004, U.S. Environmental Protection Agency, USA. 91 p.

Choudhary, A.; Gokhale, S. 2016. Urban real-world driving traffic emissions during interruption and congestion, Transportation Research Part D: Transport and Environment 43: 59-70.

CPCB. 2009. National Ambient Air Quality Standards. Central Pollution Control Board, New Delhi, India. 4 p.

CTS. 2008. Comprehensive Transportation Study for Mumbai Metropolitan Region. World Bank Project, India. $40 \mathrm{p}$.

EPA. 1995. User's Guide for The Industrial Source Complex (ISC3) Dispersion Models. Volume I, EPA454/B-95-003a. USEPA, USA.

Gokhale, S. 2011. Traffic flow pattern and meteorology at two distinct urban junctions with impacts on air quality, Atmospheric Environment 45(10): 1830-1840.
Gokhale, S. 2012. Impacts of traffic-flows on vehicularexhaust emissions at traffic junctions, Transportation Research Part D: Transport and Environment 17(1): 21-27.

Gulia, S.; Nagendra, S.S.; Khare, M.; Khanna I. 2015. Urban air quality management- a review, Atmospheric Pollution Research 6(2): 286-304.

IRC. 1990. Guidelines of Capacity of Urban Roads in Plain Areas, In Proceedings of the Indian Road Congress, New Delhi, 106.

Joseph, A.; Sawant, A.D.; Srivastava, A. 2003. PM 10 and its impacts on health - a case study in Mumbai, International Journal of Environmental Health Research 13(2): 207-214.

Kumar, R.; Joseph, A.E. 2006. Air pollution concentrations of $\mathrm{PM}_{2.5}, \mathrm{PM}_{10}$ and $\mathrm{NO}_{2}$ at ambient and Kerbsite and their correlation in Metro City, Mumbai, Environmental Monitoring and Assessments 119(1-3): 191-199.

Kumar, A.; Dikshit, A.K.; Fatima, S.; Patil, R. S. 2015. Application of WRF model for vehicular pollution modelling using AERMOD, Atmospheric and Climate Sciences 5: 57-62.

Kumar, A.; Gupta, I.; Brandt, J.; Kumar, R.; Dikshit, A.K.; Patil, R.S. 2016. Air quality mapping using GIS and economic evaluation of health impact for Mumbai city, India, Journal of the Air and Waste Management Association 66(5): 470-481.

Kumar, A.; Patil, R.S.; Dikshit, A.K.; Islam, S.; Kumar, R. 2016. Evaluation of control strategies for industrial air pollution sources using American Meteorological Society/Environmental Protection Agency Regulatory Model with simulated meteorology by Weather Research and Forecasting Model, Journal of Cleaner Production 116: 110-117. 
Ma.J.; Yi, H.; Tang, X.; Zhang, Y.; Xiang, Y.; Pu, L. 2013. Application of AERMOD on near future air quality simulation under the latest national emission control policy of China: a case study on an industrial city, Journal of Environmental Sciences 25(8): 1608-1617.

Mohan, M.; Bhati, S.; Sreenivas, A.; Marrapu, P. 2011. Performance evaluation of AERMOD and ADMS-Urban for total suspended particulate matter concentrations in Megacity Delhi, Aerosol and Air Quality Research 11(7): 883-894.

Mokhtar, M. M.; Hassim, M. H.; Taib, R. M. 2014. Health risk assessment of emissions from a coal-fired power plant using AERMOD modelling, Process Safety and Environmental Protection 92(5): 476-485.

Mohan, R. A.; Ramachandra, R.K. 2012. Measuring Urban Traffic Congestion - a Review, International Journal of Traffic and Transportation Engineering 2(4): 286-305.

MSRDC. 2006. Western Freeway Sea Link, Pedar Road viaduct Rapid Environmental Impact Assessment, Maharashtra State Road Development Corporation Limited (MSRDC), Mumbai, India.

MVD. 2013. Statistics, Motor Vehicle Department, Maharashtra, India. 96 p. Available from internet: < http://mahatranscom.in/pdf/MVD\%20Statistics\%20 -\%202012-13.pdf>.
Nagendra, S.M.S.; Khare, M. 2002. Line source emission modelling, Atmospheric Environment 36(13): 2083-2098.

NGT. 2015. Ambient Air Quality Modelling and Traffic Studies around Worli Sea Face Area. Mumbai, India.

Pawar, D.S.; Patil, G.R. 2015. Pedestrian temporal and spatial gap acceptance at mid-block street crossing in developing world, Journal of Safety Research 52: 39-46.

Patankar, A.M.; Trivedi, P.L. 2011. Monetary burden of health impacts of air pollution in Mumbai, India: implications for public health policy, Public Health 125(3): 157-64.

Seangkiatiyuth, K.; Surapipith, V.; Tantrakarnapa, K.; Lothongkum, A.W. 2011. Application of the AERMOD modeling system for environmental impact assessment of $\mathrm{NO}_{2}$ emissions from a cement complex, Journal of Environmental Sciences 23(6): 931-940.

Sharma, N.; Chaudhry, K.K.; Rao, C.C. 2004. Vehicular pollution prediction modelling: a review of highway dispersion models, Transport Reviews 24(4): 409-435.

Sivacoumar, R.; Thanasekaran, K. 1999. Line source model for vehicular pollution prediction near roadways and model evaluation through statistical analysis, Environmental Pollution 104(3): 389-395. 